\title{
THE HORSERADISH FLEA BEETLE IN SASKATCHEWAN
}

LARRY BURGESS, Agriculture Canada Research Station, Saskatoon, Saskatchewan, S7N OX2

Flea beetles are leaf eating beetles characterized by their enlarged hind legs and ability to leap into the air when disturbed. There are a number of species of these beetles in Saskatchewan, and while some feed on several different host plants, others feed exclusively or almost exclusively on a single plant species. The horseradish flea beetle (Phyllotreta armoraciae) (Koch) is one of the latter, and as its name implies, it feeds on horseradish (Armoraciae rusticana), which can occasionally be found in gardens and old or abandoned farm yards throughout the more settled parts of the province. This beetle is about 3-3.5 mm long, oval in shape, and when viewed from above has a black head and thorax and a central black stripe extending posteriorly along the inner margins of the two golden yellow wing covers (Figure 1). Feeding by these beetles leaves horseradish leaves riddled with holes (Figure 2). Similar damage to horseradish leaves is also caused by the crucifer flea beetle, (Phyllotreta cruciferae) (Goeze), which, however, is considerably smaller than the horseradish flea beetle, and recognizable by its solid black colour with a bluish lustre. Although we have found the horseradish flea beetle feeding only on horseradish, here is a possibility that it may feed on some of the cresses as apparently marsh cress (Radicula palustris) is one of its host plants. ${ }^{2}$

The horseradish flea beetle is an ntroduction from Europe, and was irst recorded in North America in
1883 from Chicago near the grounds of the Columbia Exposition. ${ }^{1}$ In 1910 A. F. Winn of Westmount, Quebec, reported that numbers of these beetles infested some horseradish seedlings he had grown from roots purchased at Bonsecours Market in Montreal, and that he later found some on a horseradish plant along a roadside. ${ }^{4}$ By 1917 it had been reported from Wisconsin and other states south of the Great Lakes as well as Nebraska, lowa and New Jersey. ${ }^{2}$ The date of its arrival in Saskatchewan is uncertain; the earliest collected specimen in the Saskatoon Research Station's collection is dated 1944 and is from Moose Jaw. The first report of this beetle in British Columbia was in 1968. ${ }^{3}$ In Saskatchewan, Ed Wiens and I have collected it from horseradish in a number of locations in the central part of the province, including Blaine Lake, Duck Lake, Fish Creek, Saskatoon, St. Denis and Donavon. Ed was unable to find any of these beetles on a patch of horseradish at Wymark in the southwestern part of the province. Similarly, we could not find any on a patch of horseradish growing close to the warden's cabin at Crean Lake in the boreal forest of Prince Albert National Park. These beetles are occasionally present in the boreal forest however, as we have taken one specimen in a trap beside the La Ronge highway to the west of Montreal Lake.

The horseradish flea beetle overwinters as an adult beetle in the soil, turf or leaf litter. In the middle of 


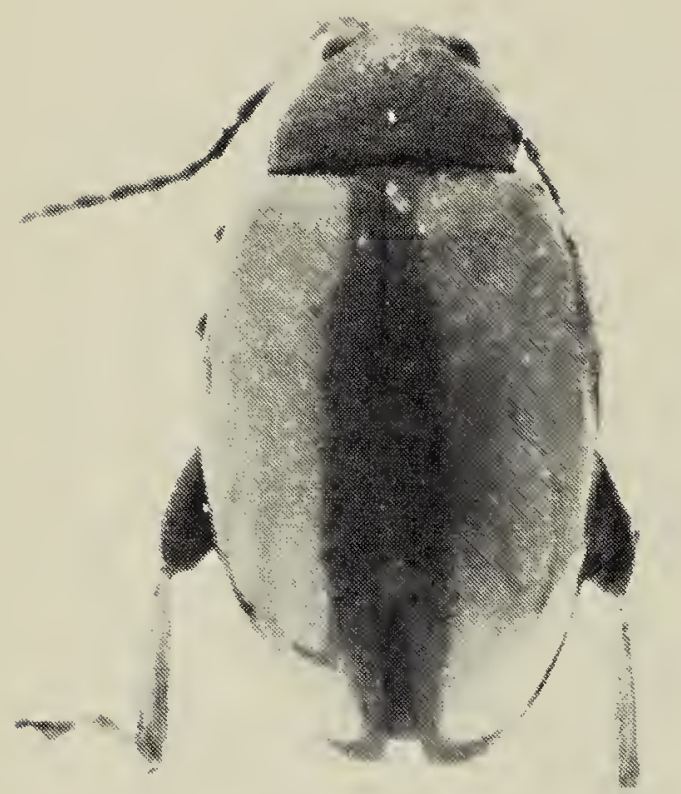

$1 \mathrm{~mm}$

1

September we have found these beetles in soil around the base of horseradish plants and in late February in turf, and in leaf litter beneath a carragana hedge. The latest we have found this beetle moving about on horseradish plants in the autumn was 4 November, 1975, a warm sunny day with a temperature of $14^{\circ} \mathrm{C}$. In the spring the overwintered beetles become active with the arrival of warm sunny weather and we have seen them mating and feeding actively on horseradish shoots near Blaine Lake on 3 May.

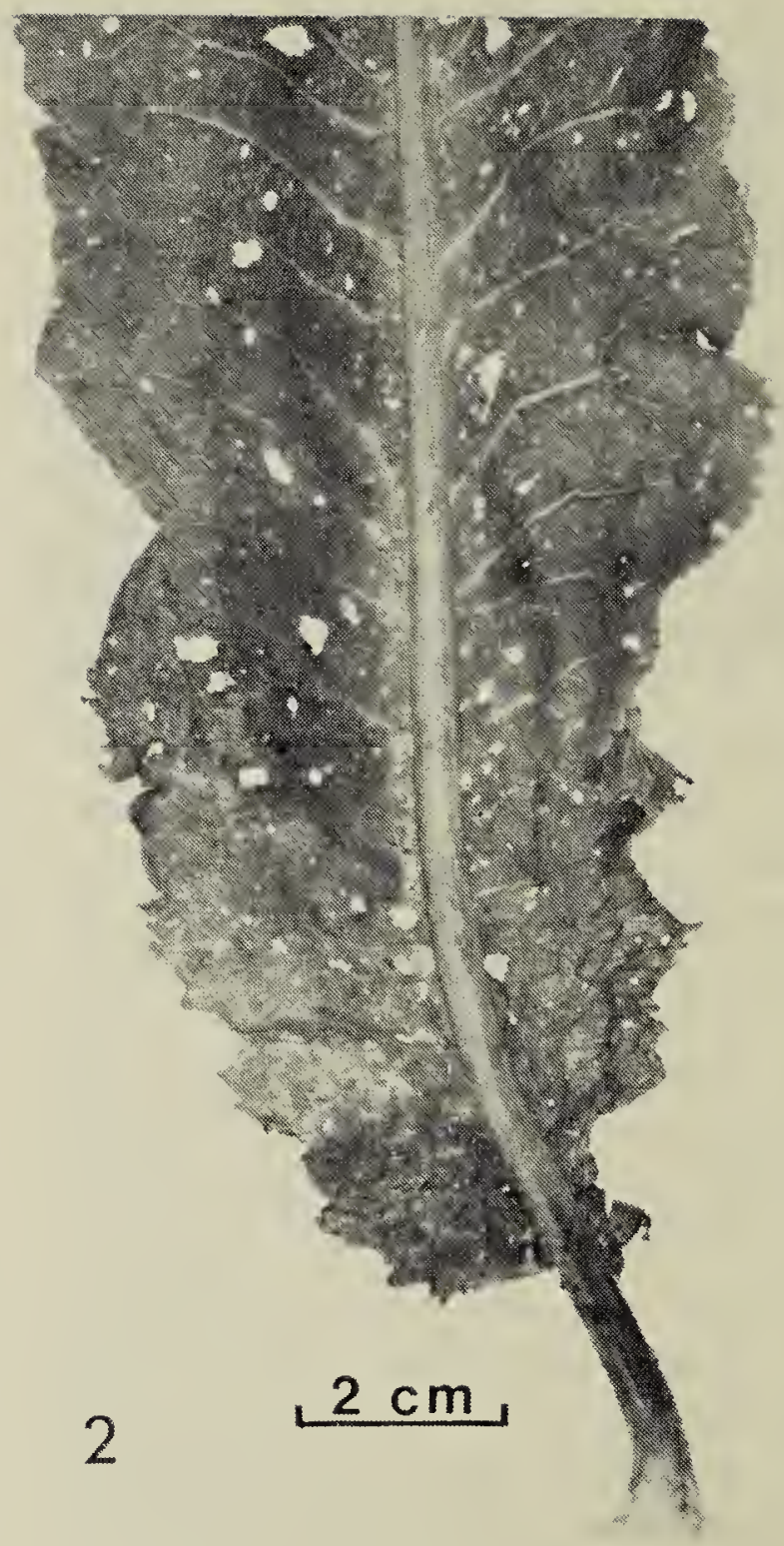

Ralph R. Underwoo

Figure 1. Adult horseradish flea beetle collected near Donavon, Saskatchewan.

Figure 2. Portion of a horseradish leaf showing flea beetle damage, caused probably b both horseradish and crucifer flea beetles.

Some of these beetles collected in vial had begun laying their dee yellow eggs by 6 May and by 9 Jun larvae were found mining the petiole and midribs of a horseradish plant $i$ a cage to which the eggs and adult had been introduced. Chittende gives a good account of the life history of this insect. ${ }^{2} \mathrm{He}$ recorde one female as laying 418 eggs. $H$ observed that the larvae, when near ing maturity, leave their mines in th petioles and midribs of the horse radish leaves and enter the soi where they pupate. Later in th 
season the new adults emerge, and Chittenden recorded the time between egg laying and adult emergence as ranging from 77 to about 90 days. Upon emergence adults feed for a while and then enter their over-wintering quarters. In Saskatchewan, as in Wisconsin where Chittenden studied them, these beetles have only one generation per year.

While the horseradish flea beetle can be a serious pest where horseradish is grown commercially, in Saskatchewan, where much of the horseradish used as a relish is obtained as a prepared product from grocery store shelves, the horseradish flea beetle is another of Nature's creatures that lives more or less harmoniously with man.

\section{Acknowledgements}

I thank Mr. J. E. Wiens for his assistance and interest in these observations, Mr. Ralph E. Underwood for his kindness. in taking the photographs, and Parks Canada for their kind permission to study flea beetles in Prince Albert National Park.

${ }^{1}$ CHITTENDEN, F. H. 1895. The horseradish flea-beetle. Insect Life 7:404406.

${ }^{2}$ CHITTENDEN, F. H. 1917 . The horseradish flea-beetle: Its life history and distribution. United States Department of Agriculture Bulletin Number 535.

${ }^{3}$ LAZORKO, W. 1973. Three species of Coleoptera new to British Columbia. Journal of the Entomological Society of British Columbia 70:41.

${ }^{4}$ WINN, A. F. 1910. The horse-radish fleabeetle (Phyllotreta armoraciae, Koch). Forty-first Annual Report of the Entomological Society of Ontario: 59-60.

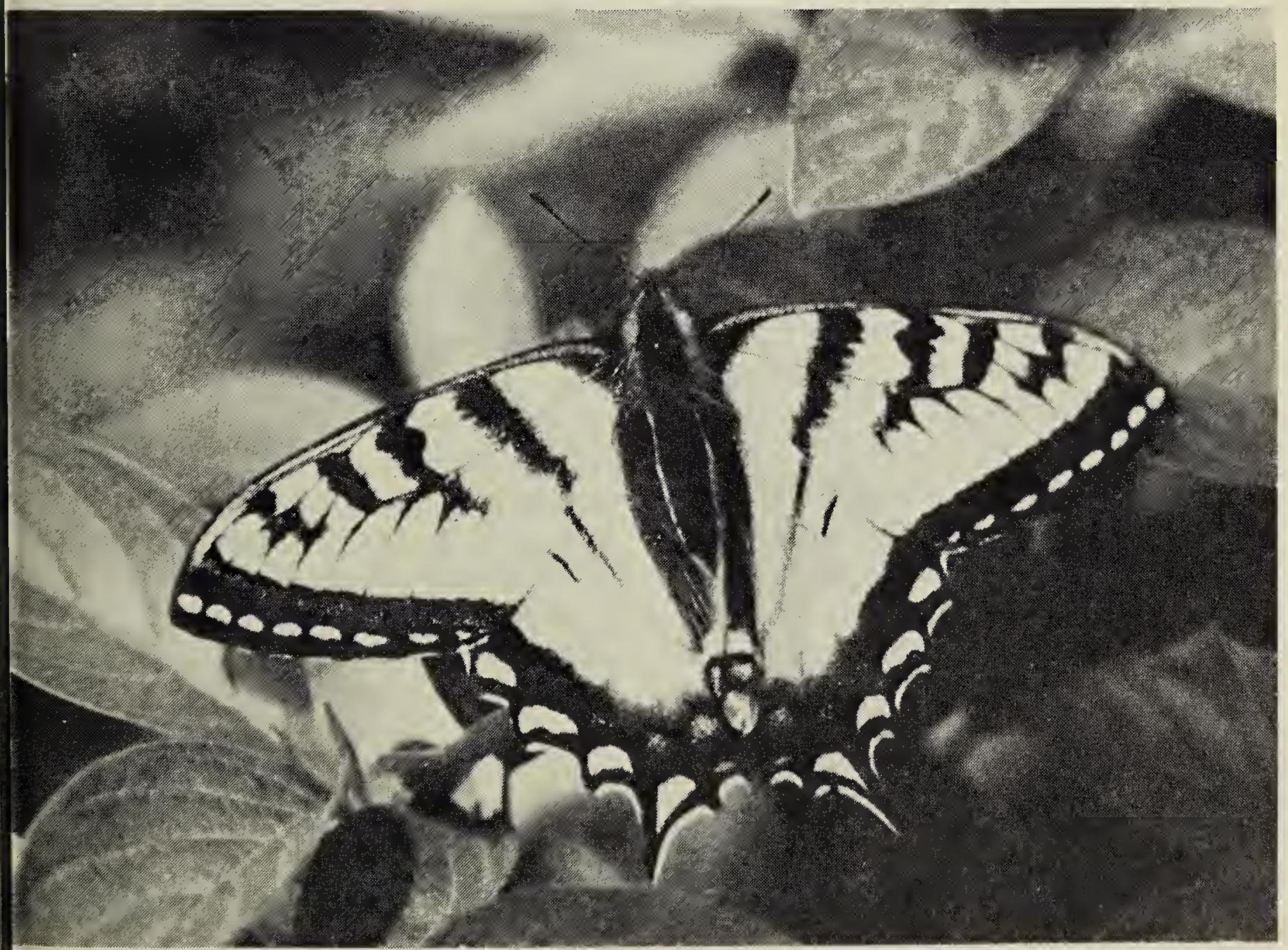

